\title{
TOTALITARISMO EM THE HANDMAID'S TALE: ENTRE MANIPULAÇÃO E PROGRAMAÇÃO
}

\author{
Natália Silva Giarola de Resende ${ }^{1}$ \\ Conrado Moreira Mendes ${ }^{2}$
}

RESUMO: Neste trabalho, com base nos regimes de interação e sentido da teoria sociossemiótica (LANDOWSKI, 2014), temos como objetivo compreender como se constitui o regime totalitário de Gilead, nação fictícia da série distópica The Handmaid's Tale, com base na análise do primeiro episódio, intitulado Offred. A partir da articulação entre os fundamentos teóricos - totalitarismo (ARENDT, 2012; NEUMANN, 1969; TURPIN, 2012) e sociossemiótica - e das reflexôes resultadas da análise, verificamos que tanto o regime da manipulação quanto o da programação legitimam a conservação do Estado totalitário.

PALAVRAS-CHAVE: Sociossemiótica. Manipulação. Programação. Totalitarismo. The Handmaid's Tale.

\section{TOTALITARISM IN THE HANDMAID'S TALE: BETWEEN MANIPULATION AND PROGRAMMING}

ABSTRACT: In this paper, based on the regimes of meaning and interaction from sociosemiotics theory (LANDOWSKI, 2014), we aim to understand how the totalitarian regime of Gilead, a fictional nation in the dystopian series The Handmaid's Tale, is constituted, taking as object of analysis the first episode, entitled Offred. From the articulation betwe-

1 Universidade Federal de Minas Gerais (Ufmg), Belo Horizonte - MG - Brasil. Doutoranda em Linguística, subárea Análise do Discurso e Semiótica de linha francesa. Orcid: https://orcid.org/0000-0001-7768-8091. nati. giarola@gmail.com.

2 Pontifícia Universidade Católica (Puc Minas), Poços de Caldas - MG - Brasil. Professor do Programa de Pós-graduação em Comunicação Social; Universidade de São Paulo (Usp), São Paulo - SP - Brasil. Doutor em Semiótica e Linguística Geral. Orcid: https://orcid.org/0000-0002-3721-8578. conradomendes@yahoo.com.br. 
en the theoretical foundations - totalitarianism (ARENDT, 2012; NEUMANN, 1969; TURPIN, 2012) and sociosemiotics - and the reflections resulting from the analysis, we verified that both the manipulation and programming regimes legitimize the conservation of the totalitarian state.

KEYWORDS: Sociosemiotics. Manipulation. Programming. Totalitarianism. The Handmaid's Tale.

\section{Considerações iniciais}

Considerando o dossiê temático "O fazer enunciativo diante de desafios sociais contemporâneos: como discursos políticos e sociais passaram a ser moldados”, neste artigo, partimos da análise de um episódio da série de ficção The Handmaid's Tale para, por interdiscursividade, tocar em um tema extremamente atual e não ficcional: a ascensão da extrema direita no mundo. Donald Trump, nos EUA, Jair Bolsonaro, no Brasil, Viktor Orbán, na Hungria, Recep Tayyip Erdogan, na Turquia, são alguns exemplos da guinada à direita do mundo na atualidade, movimento que, por vezes, também se faz rumo ao totalitarismo, que, neste trabalho, entendemos como ideia de monopólio do poder, por meio do medo e da ideologia (ARENDT, 2012; NEUMANN, 1969; TURPIN, 2012). Manter um regime totalitário a qualquer custo é do que fala The Handmaid's Tale.

Baseado no romance homônimo da autora canadense Margaret Atwood, de 1985, traduzido para o português como O Conto de Aia, a série, criada por Bruce Miller e produzida e distribuída pela plataforma de streaming Hulu, estreou em 2017. No Brasil, foi exibida pela HBO e está disponível na plataforma de streaming GloboPlay. The Handmaid's Tale tem sua trama ambientada num futuro em que a humanidade sofre com as baixas taxas de natalidade. Em meio a isso, os Estados Unidos sofrem um golpe parlamentar dos chamados "Filhos de Jacob”, uma instituição religiosa e totalitária, que institui um novo Estado, a República de Gilead, em que os cidadãos são submetidos a novas regras, como a separação da sociedade em castas. Nesse sistema, as mulheres são tidas como propriedade do Estado, sendo dominadas pelo Governo, figurativizado pelo homem branco e poderoso. Subjugadas às novas normas, as poucas mulheres férteis, para sobreviver, tornam-se "Aias", cuja função é a servidão sexual com o objetivo de procriar. 
Diante desse panorama, consideramos a sociossemiótica de Eric Landowski (2014) e seus regimes e interação para responder à questão: como se constitui o regime totalitário de Gilead? Para isso, na primeira parte do trabalho, apresentamos a descrição do primeiro episódio. Em seguida, expomos um breve panorama sobre o totalitarismo, seguido dos pressupostos da sociossemiótica para, por fim, elaborar um percurso analítico que nos leve a responder o problema proposto e, finalmente, apresentar nossas consideraçóes.

\section{Offred. algumas palavras sobre o primeiro episódio}

O primeiro episódio de The Handmaid's Tale, intitulado Offred, foi dirigido por Reed Morano e exibido no dia 26 de abril de 2017. Como é o primeiro contato do telespectador com a história, o capítulo oscila entre o presente e passado, por meio de flashbacks. Em sua cena inicial, a personagem, até entáo desconhecida, encontra-se em fuga com um homem e uma criança. Devido à quantidade de gelo na pista, o veículo em que estavam se envolve em um acidente. Então, a mulher e a criança correm para a floresta, deixando o homem sozinho, a pedido dele mesmo. Depois disso, há disparos de tiros e homens armados e uniformizados encontram a mulher e a criança, mãe e filha. Após uma luta entre os guardas e a mãe, ambas são capturadas e levadas separadamente. Nesse momento, ouve-se o nome da filha, Hannah (Jordana Blake) (Figura 01).

Figura 1 - June tenta proteger sua filha Hannah de ser capturada pelas autoridades de Gillead.

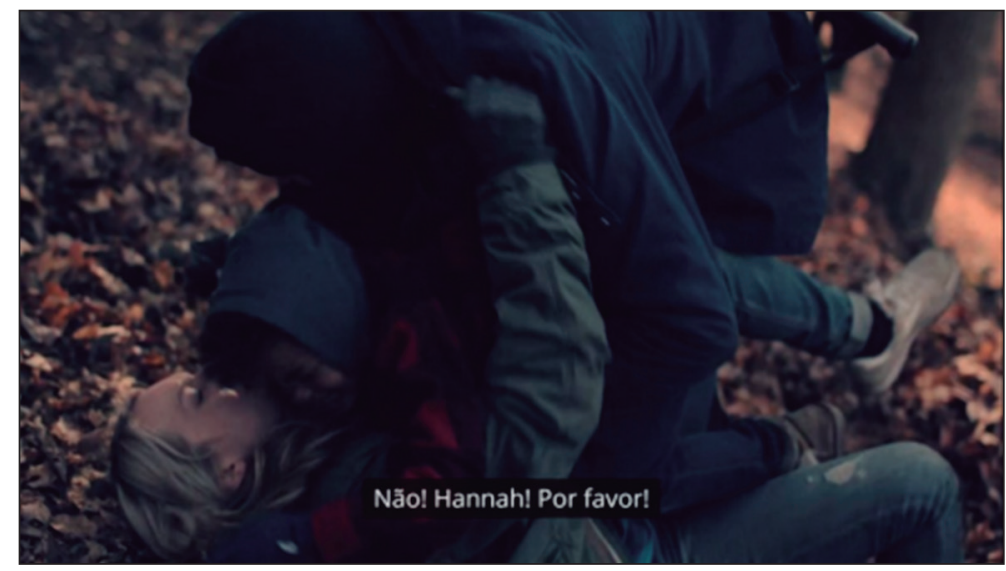

Fonte: (THE HANDMAID'S..., 2016). 
Nas cenas seguintes, identifica-se que a mulher é June Osborne (Elisabeth Moss) e o homem seu marido Luke (O. T. Fagbenle) e ambos tentavam fugir, junto com filha Hannah, da Republica de Gilled ${ }^{3}$. Capturada, June é levada ao Centro Vermelho, gerenciado pelas Tias, responsáveis pelo treinamento das Aias. No centro, as Aias são ensinadas a como devem servir aos líderes governamentais e as suas esposas estéreis.

Lá, June (Offred) reencontra sua melhor amiga, Moira (Samira Wiley), a quem conta que passou a se chamar Offred. Moira explica a ela que resistir não valia a pena, já que poderia sofrer violência física e até ser morta. Portanto, segundo Moira, se Offred/June desejasse reencontrar sua filha, deveria se submeter às regras para sobreviver. Nas cenas seguintes, vemos Offred sendo enviada para a casa do Comandante Fred Waterford (Joseph Fiennes) e de sua esposa Serena Joy Waterford (Yvonne Strahovski).

O Comandante Fred foi um dos homens responsáveis pela instauração do governo e Offred foi enviada para sua casa, pois, além de ser fértil, era considerada pecadora, já que seu antigo marido, Luke, era casado quando eles começaram a se envolver. Desse modo, servir a um dos homens mais poderosos de Gilead é uma forma de redenção. A partir desse ponto, as narrativas de Offred voltam-se para a rotina de Gilled, tais como o convívio com a Esposa, o Comandante, as compras que fazia no supermercado, sempre acompanhada de outra Aia, Ofglen (Alexis Bledel), além da cerimônia ${ }^{4}$.

De maneira geral, o primeiro episódio nos mostra que a sociedade é patriarcal e regida pelas leis do "Antigo Testamento", tal como mostra a figura 03.

Figura 2 - Comandante Fred lê uma passagem do antigo testamento

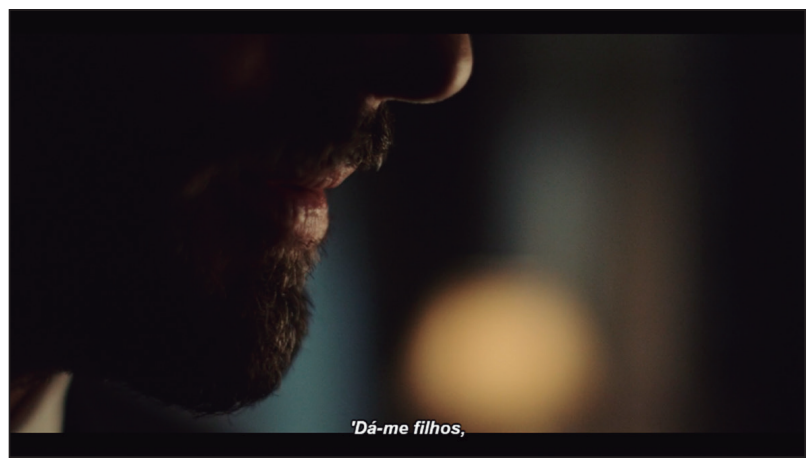

Fonte: (THE HANDMAID'S..., 2016).

\footnotetext{
3 Neste primeiro episódio, o paradeiro do marido e da filha não são revelados.

4 A ser explicada ainda nesta seção.
} 
Nela, o Comandante Fred faz uma referência à passagem bíblica do Livro de "Gênesis", versículo 30.

Quando Raquel viu que não dava filhos a Jacó, teve inveja de sua irmã. Por isso disse a Jacó: “Dê-me filhos ou morrerei!" Jacó ficou irritado e disse: "Por acaso estou no lugar de Deus, que a impediu de ter filhos?" Então ela respondeu: "Aqui está Bila, minha serva. Deite-se com ela, para que tenha filhos em meu lugar[a] e por meio dela eu também possa formar família”. Por isso ela deu a Jacó sua serva Bila por mulher. Ele deitou-se com ela, Bila engravidou e deu-lhe um filho. Então Raquel disse: "Deus me fez justiça, ouviu o meu clamor e deu-me um filho” (A BIBLIA, 2018, p. 1110).

$\mathrm{Na}$ série, as Aias são como Bila que, na passagem bíblica, tem a função de reprodução. $\mathrm{O}$ ato sexual a que as Aias são submetidas recebe o nome de Cerimônia e acontece mensalmente, até que a Aia engravide, tenha a criança e seja deslocada para outra residência, com o mesmo intuito, isto é, ser uma espécie de ponte sexual entre a Esposa e o Comandante. Além disso, no primeiro episódio, fica evidente a divisão de classe entre as mulheres da série.

De acordo com Graton (2018), na sociedade de Gilead as mulheres não podem ler, escrever, trabalhar ou serem donas de qualquer tipo de bem ou propriedade. Ademais, há quatro principais classes sociais em que as mulheres podem se enquadrar. A primeira são as Aias, únicas mulheres férteis, por isso são escravizadas e dominadas. Já Marthas são mulheres que possuem o papel de empregadas e governantas nas casas dos comandantes. Já as Tias, representadas pela figura da Tia Lydia (Ann Dowd), são compostas "por mulheres que apoiam e concordam com as ideias de Gilead, e tem como seu principal trabalho instruir e controlar as Aias" (GRATON, 2018, p. 63). As Esposas dos Comandantes, por fim, consideradas como a maior classe entre as mulheres. Elas possuem como função cuidar da casa e da família, sendo responsáveis pelo controle das Aias e das Marthas. Em The Handmaid's Tale, Serena Joy é a Esposa que tem o papel mais relevante, uma vez que é casada com o comandante Fred Waterford.

Além dessas quatro classes principais ${ }^{5}$, Graton (2018) explica que ainda existem as Jezebels: prostitutas que trabalham e vivem em bordéis. Há também as Econoesposas, "mulheres férteis de classes mais baixas que possuem o direito básico de poder viver com as suas famílias em casas simples pois são religiosas e nunca fizeram nada considerado 'pecado' em Gilead” (GRATON, 2018, p.

5 Essas três próximas classes não aparecem no primeiro episódio. Trouxemos ao texto apenas a título de conhecimento. 
64). A última classe e a mais subjugada é composta pelas Não-mulheres, que são mulheres não férteis ou que praticaram algum crime contra o governo. Normalmente, elas vivem nas colônias - campo de concentração de Gilead - e são obrigadas a trabalharem com material tóxico.

\section{Breves considerações sobre o totalitarismo}

Para explicar o totalitarismo, Hannah Arendt, em seu livro Origens do totalitarismo (2012), parte de dois fatos históricos do século XX, o nazismo e o stalinismo, além de apontar o antissemitismo - o ódio extremo aos judeus - como um potencializador do nazismo, que teve como resultado a Segunda Guerra Mundial e o extermínio dos judeus em campos de concentração.

Arendt define o totalitarismo como "uma forma inteiramente nova de governo" (ARENDT, 2012, p. 531), a qual se constitui na ausência de outros poderes, uma vez que o governante do Estado é a autoridade máxima, não pode ser questionado e que age de forma a dominar sua população. A autora acrescenta que o "domínio totalitário, visa à abolição da liberdade até mesmo a abolição de toda espontaneidade humana e náo a simples restrição, por mais tirânica que seja, da liberdade" (ARENDT, 2012, p. 455).

Para que essa máquina totalitária engrene, é necessário que ela esteja embasada no binômio terror e ideologia: "o terror torna-se total quando independe de toda oposição; reina supremo quando ninguém mais lhe barra o caminho. Se a legalidade é a essência do governo não tirânico e a ilegalidade é a essência da tirania, então o terror é a essência do governo totalitário" (ARENDT, 2012, p. 517).

Desse modo, para Arendt (2012), a imposição do terror e a solidificação de uma ideologia dominante definem o totalitarismo e garantem sua permanência. Assim, ao implantar um regime totalitário, há uma destruição das tradiçóes políticas, legais e sociais até então vigentes em um país. O futuro se torna incerto, uma vez que a sociedade está sob comando de entidades políticas que "podem a qualquer instante fugir às regras do bom senso e do interesse próprio - forças que pareceriam insanas se fossem medidas pelos padrôes dos séculos anteriores" (ARENDT, 2012, p. 7).

Outro autor que aborda o tema do totalitarismo é Franz Neumann. Em seu livro Estado Democrático e Estado Autoritário (1969), ele elenca cinco características essenciais de uma ditadura totalitária: 
1) transição de um estado de direito para um estado policial; 2) transição do poder difuso nos estados liberais para a sua concentração no regime totalitário; 3) a existência de um partido estatal monopolista; 4) transiçấo dos controles sociais que passam de pluralistas para totalitários; 5) a presença decisiva do terror como ameaça constante contra o indivíduo (NEUMANN, 1969, p. 268).

O que o autor nos diz é que, em sua base, o totalitarismo surge de uma oposição entre um Estado liberal para um Estado radical. Assim, o que evidencia o totalitarismo é "destruição da linha entre o Estado e a sociedade, e a total politização dessa sociedade por meio do partido único” (NEUMANN, 1969, p. 70). Em outros termos, enquanto houver prevalência da sociedade civil, temos um regime liberal. Por outro lado, quando o Estado domina, há o totalitarismo.

Assim, se, por um lado, o Estado liberal se constitui pela lei, pela razáo e pela liberdade, além da difusão do poder e de uma estrutura política em que existe pluralidade de partidos, por outro, o Estado totalitário exclui toda a constituição do Estado liberal e instaura um sistema de valores no qual prevalece a violência extrema, simbolizada pelo terror, e a estrutura política é baseada no monopólio político, formada por apenas um partido.

$\mathrm{Na}$ linha da Análise do Discurso, a francesa Béatrice Turpin, a partir do estudo de obras do autor Victor Klemperer, como, por exemplo, A Linguagem do Terceiro Reich, traça alguns aspectos essenciais da linguagem totalitária:

[...] as observaçóes de Klemperer nos permitem circunscrever algumas características que nos parecem específicas ao totalitarismo e que formam o que chamamos aqui de uma semiótica da linguagem totalitária. Sáo estes os traços: a linguagem totalitária investe em todos os canais e suportes; investe também nas esferas públicas como nas esferas privadas; possui uma homogeneidade assustadora; está irredutivelmente ligada à violência e à morte. É uma linguagem que sente o sangue e a morte, como diria Klemperer; é uma linguagem forçada, a-histórica, inteiramente ideológica; ela afasta o sujeito do seu próprio pensamento; é uma linguagem do tipo místico (TURPIN, 2012, p. 66-67, tradução nossa) ${ }^{6}$.

\footnotetext{
6 No original: “[...] les observations de Klemperer nous permettent de circonscrire des caractéristiques qui nous semblent être spécifiques au totalitarisme et qui forment ce que nous appelons ici une sémiotique du langage totalitaire. Ces traits sont les suivants: le langage totalitaire investit tous les canaux, tous les supports; il investit les sphères tant publiques que privées; ce langage a une 'homogénéité effroyable'; il est irréductiblement lié à la violence et à la mort. C'est un langage qui 'sent le sang e la mort', dira Klemperer; c'est un langage
} 
O que a autora nos evidencia é que a linguagem totalitária está ligada ao regime político vigente e destaca marcas do autoritarismo, da intolerância e do pensamento fascista. Ou seja, esses discursos - autoritário, intolerante e fascista - têm como função legitimar a ideologia totalitária e rejeitar qualquer outro discurso que seja diferente dele, tendo sua base na violência.

\section{Regimes de interação e sentido}

Depois de termos apresentado o episódio e alguns elementos sobre o totalitarismo, passamos agora à explanação de alguns pressupostos teóricos da sociossemiótica, sobre os quais e ancora a análise do seriado em questão.

A sociossemiótica tem como principal característica o "fato de considerar a interação como o lugar mesmo da aparição do sentido" (LANDOWSKI, 2014 , p. 353 $)^{7}$. Como um desdobramento da teoria semiótica discursiva de linha francesa, ela versa sobre as interaçóes, no âmbito do nível narrativo. A teoria semiótica, tal como concebeu Greimas, edificou-se a partir de uma gramática narrativa, por meio das operaçóes de junção, que ora podem colocar em posse os sujeitos com os objetos (conjunção) e ora em privação (disjunção). Ao lado da lógica da junção, Eric Landowski propóe a lógica da união, que serve de alicerce para outros dois regimes não previstos na semiótica greimasiana: o ajustamento e o acidente:

Segundo a lógica da junção, a compreensão do mundo passa pelo deciframento de formas que, verbais ou não, são consideradas como equivalentes a outros tantos textos que, supostamente, «quereriam» dizer-nos qualquer coisa. Ao contrário, segundo a lógica da uniáo, nós não olhamos mais, ou não ainda, o mundo como uma rede de significantes a decifrar (LANDOWSKI, 2014, p. 13).

Assim, o que Landowski (2014) propóe é que determinadas situações não se deixam apreender apenas o regime da junção, o qual é baseado pela mediação do de objeto-valor (relação objetal). Para ele, existe uma relação subjetiva, alicerçado na copresença sensível dos actantes.

Posto isso, o viés teórico-metodológico que sustenta o presente trabalho é embasado nos estudos sobre os regimes de sentido e interação desenvolvidos por

forcé, anhistorique, entièrement idéologique; il désinvestit le sujet de sa propre pensée; c'est un langage de type mystique». (TURPIN, 2012, p. 66-67).

Definição de sociossemiótica, em entrevista concedida a Silva (2014) nos Casa: Cadernos de Semiótica Aplicada. 
Eric Landowski no livro Interaçóes Arriscadas (2014), cuja articulação constitui uma sintaxe das interaçóes, sejam as pautadas pelo inteligível, sejam as pautadas pelo sensível.

O primeiro regime, o da programação, visa à interação sem risco, regida pela regularidade. Ele é fundado na previsibilidade que Greimas vislumbrava em ensaios como A soupe au pistou (GREIMAS, 2014, p. 167). Este regime é modalizado por um fazer-ser, que corresponde a uma ação considerada como operação. O segundo regime é aquele da manipulação, de um fazer-fazer compreendido em termos de intersubjetividade e de interioridade. Como explica Landowski:

Enquanto que, do ponto de vista narrativo, a operação se confunde com a execução de uma performance que tem como efeito direto a transformação de algum "estado de coisas", a manipulação aponta pra transformar o mundo mediante uma conduta estratégica prévia que tem em vista, se não em todos os casos os "estados de alma", ao menos a competência de outro sujeito, o "querer fazer" que o levará a agir, seja operando por sim mesmo sobre o mundo como tal, seja manipulando por sua vez outro sujeito, seja até mesmo segundo outro procedimento que ainda falta por identificar e por definir. (LANDOWSKI, 2014, p.22).

Fase inicial do esquema narrativo canônico, o regime da manipulação tem por finalidade motivar e persuadir um sujeito a agir de determinada maneira. Ela é baseada no princípio da intencionalidade, sendo dependente do estabelecimento do contrato entre os actantes. O contrato, em semiótica, é estabelecido de forma implícita entre o destinador e um destinatário. Como explica Greimas (2014), para que haja a aceitação do contrato é necessário que o destinador e o destinatário compartilhem do mesmo sistema de valores, visto que a adesão do destinatário é a única maneira de sancionar o contrato, isto é, caso contrário, há uma quebra de contrato e a manipulação não ocorre.

Para o desenvolvimento dos dois últimos regimes de interação, Landowski (2014) não abandona os pressupostos da gramática narrativa clássica, mas se volta para as questóes ligadas à estesia e aos acidentes estéticos da cotidianidade ${ }^{8}$ e postula uma nova lógica, a da união. Nesta, a interação e o sentido se constroem por meio do contato direto, do contágio e da copresença, seja por meio do acidente ou do ajustamento.

8 Elaborados por Greimas em seu livro Da Imperfeição (2017) 
No ajustamento, há um fazer-sentir, que é da ordem do sensível. Nesse regime, os parceiros participam da construção da interaçáo adaptando-se à maneira de agir um do outro. $\mathrm{O}$ ajustamento é, portanto, a interação entre iguais, na qual as partes coordenam suas dinâmicas por meio de um fazer compartilhado: "é a capacidade de se sentir reciprocamente. Para a diferenciar da competência dita modal, nós a batizamos de competência estésica" (LANDOWSKI, 2014, p. 50). Há, desse modo, uma ligação entre corpos que sentem e são sentidos, promovendo a sensibilidade.

Por fim, o regime do acidente é governado pela aleatoriedade. Ele se relaciona com a eventualidade, ou seja, uma interação ocorrida pelo acaso e que ele pode ser compreendido sob duas concepçóes. A primeira é a probabilidade matemática, na qual o acaso é visto como um fenômeno imanente e vazio de sentido, isto é, sua manifestação está interligada ao calculável. A segunda é a probabilidade mítica, em que o acaso depende de uma instância transcendente, em outras palavras ele é mantido pela fatalidade.

Destacando que a programação e a manipulação se pautam pela lógica da junção (constelação da prudência) e o ajustamento e acidente, pela lógica da união (constelação da aventura), exibimos, a seguir, a o mapa metodológico das interaçóes, proposto por Oliveira (2018) com base em Landowski (2014). Nele (Quadro 1) é possível observar a organização dos regimes a partir das lógicas da junção e da união: 
Quadro 1 - Regimes de interaçáo e sentido e suas lógicas

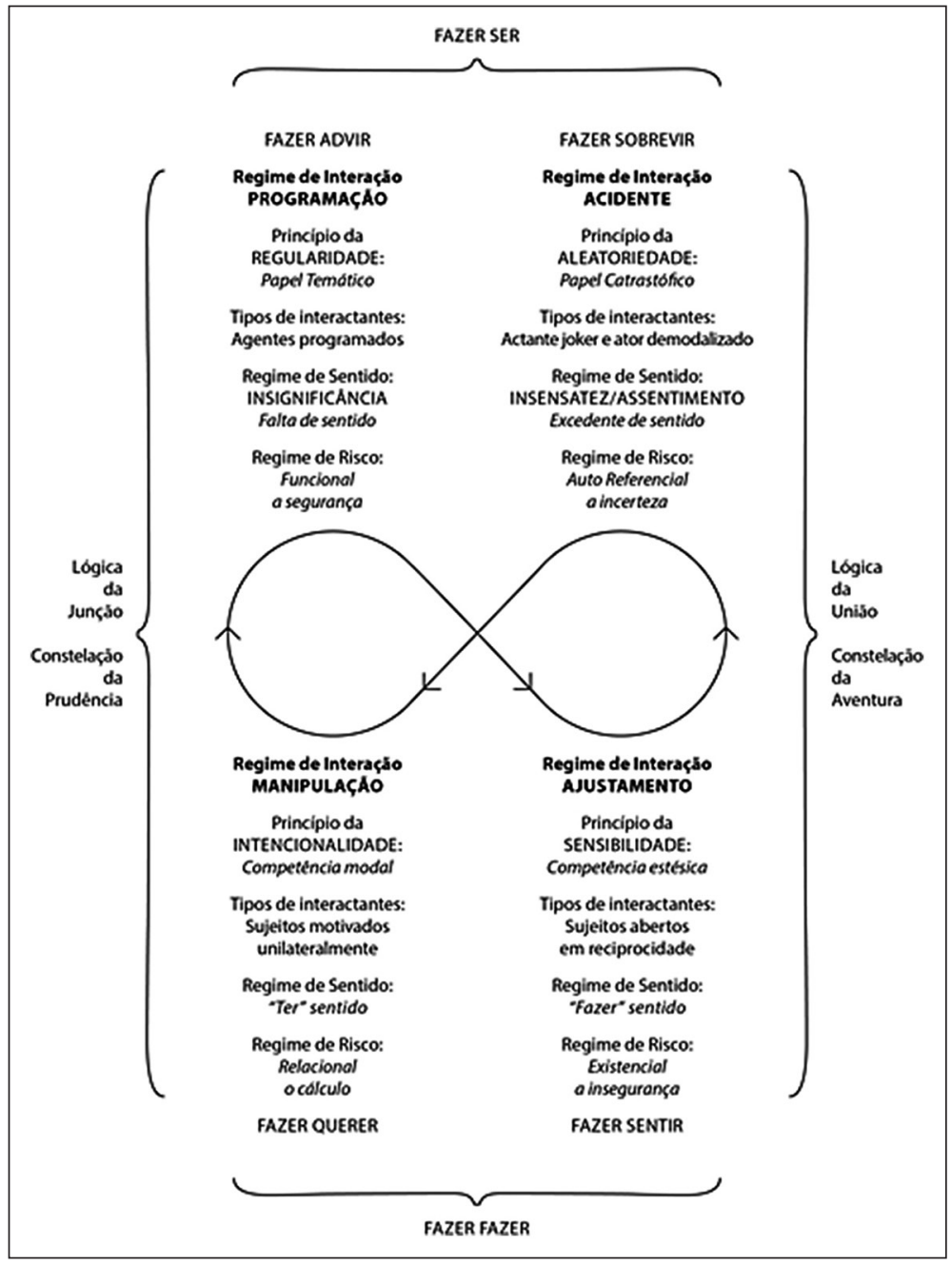

Fonte: Oliveira (2018, p. 32).

Landowski (2014) organiza seu sistema na oposição continuidade vs. descontinuidade, no qual o risco permeia os quatro regimes, em que quanto maior for a regularidade menor será o risco. Assim, na programação o risco é quase neutro, por outro lado no regime do acidente ele é o principal fator. Já a manipulação e o ajustamento ficam na zona na qual o risco está presente e pode ser um elemento de intençôes, como na manipulação, ou aceito e compreendido, como no ajustamento. $\mathrm{O}$ autor descreve da seguinte forma a dinâmica do seu modelo: 
Substituindo as linhas retas do quadrado semiótico clássico por linhas curvas, e fazendo assim aparecer zonas de trânsito em lugar das oposiçóes fixas, pontuais por definição, do esquema habitual, essa forma de apresentação visa a pôr em evidência os processos antes do que o sistema que os sustenta. A sua leitura deveria, por conseguinte, ser feita à maneira de um percurso, o qual se desenrolará em dois tempos: primeiro, a partir da zona do acidente rumo a da manipulação e, dali, seguindo até o regime da programação, ponto de chegada provisório. Este último regime, que define um mundo em que prevalecem a ordem, a estabilidade e a continuidade, pode, com efeito, ser considerado, segundo outra perspectiva (aquela adotada, como já indicado, em Da Imperfeição), como dado "na origem". Enxergado deste modo, ele constitui um ponto de partida alternativo. Daí um segundo movimento, que conduzirá desta vez da programação ao ajustamento, e finalmente, para fechar o circuito, do ajustamento de novo ao regime do acaso e do acidente (LANDOWSKI, 2014, p. 80).

Segundo Landowski (2014), há dois caminhos possíveis para seguir no quadrado, um que irá do acidente à manipulação e outro do ajustamento ao regime do acaso do acidente. Todavia, os regimes são contínuos e dinâmicos, em função disso, são esquematizados em flechas contínuas indicando que o sistema está em constante movimento, permitindo a transiçáo de um regime ao outro.

\section{Regimes de interação no episódio Offred}

Uma vez apresentado o modelo teórico-metodológico, passamos à análise do primeiro episódio de The Handmaind's Tale. Nele, somos introduzidos aos detalhes da vida pós-revolução, narrados pela protagonista June/Offred. Para compreender o suposto motivo da implantação da República de Gilead, partimos da explicaçáo feita pela Tia Lydia no centro de treinamento das Aias, sobre a existência de República de Gilead. Segundo ela, como percebemos os frames da figura 03, o mundo está enfrentando uma crise de infertilidade ${ }^{2}$ - "praga da infertilidade" - causada, entre outros motivos pelo efeito estufa e principalmente pelo uso de pílulas contraceptivas, aborto e orgias.

\footnotetext{
9 "Para se ter uma ideia da crise da infertilidade, no decorrer da primeira temporada de The Handmaid's Tale somos informados que no México apenas uma criança nasceu ao longo de seis anos” (FEITAL, 2018, p. 4).
} 
Figura 3 - Explicação sobre origem de Gilead
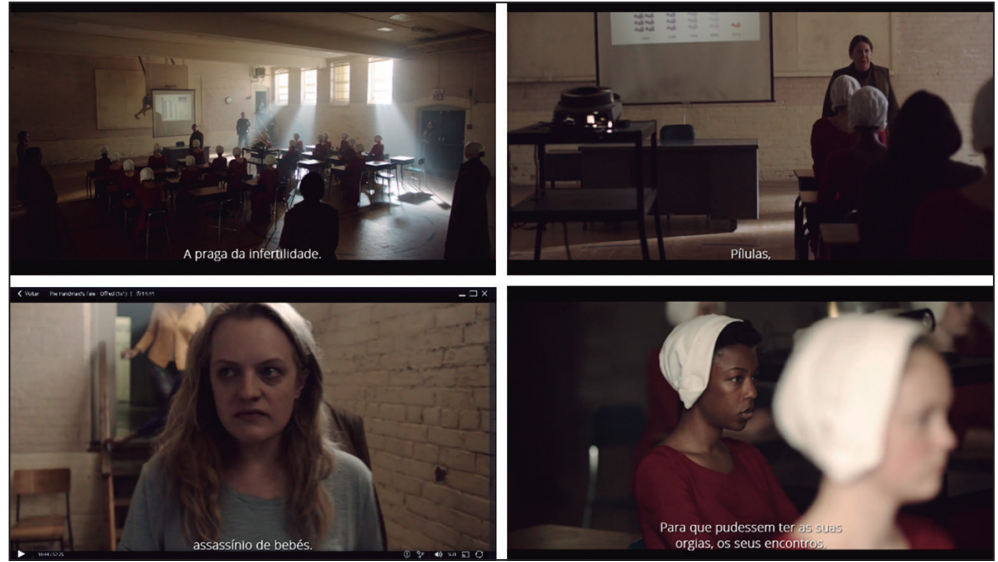

Fonte: (THE HANDMAID'S..., 2016).

A criação Gilead não é totalmente clara, porque todas as informaçôes são dadas sob o ponto de vista de June/Offred. Dessa perspectiva, podemos considerar a implantação da República como um acidente, uma vez que esse regime de interação é caracterizado pela descontinuidade total diante das constantes. Para Offred, como é possível notar em flashbacks, a sociedade vivia numa ordem, mesmo com a crise de infertilidade.

Apesar da aparente ordem, Offred relembra que o golpe dado pelos "Filhos de Jacob" aconteceu táo rapidamente que, de um dia para o outro, as mulheres, os negros, os homossexuais e outros grupos, como os cientistas, começaram a ser caçados e expulsos de seus trabalhos e casas. Tudo isso aconteceu de uma maneira tão célere que a população não conseguia compreender o que estava acontecendo, criando uma desordem no país. O regime do acidente está intimamente ligado à intranquilidade, instabilidade, agitação e ao caos, causando uma perturbação no sujeito que sente. Ele não produz um sentido de imediato, tudo é inesperado, com um sentido excessivo e, temporariamente, indecifrável.

O regime da manipulação rege a inserção das Aias e de Offred no novo modelo imposto pelas leis de Gilead. Na manipulação, as interaçôes implicam o princípio da intencionalidade que, nesse caso, é manifestado em estratégias de intimidação pelo sujeito manipulador que ora são as Tias, ora os Comandantes e ora as Esposas. Todos esses intimidam dotando o destinatário "Aias" de um dever-fazer, ou seja, submeter-se às regras do Estado. Em caso de não cumprimento desse contrato, elas poderiam ser enviadas para as Colônias para trabalho escravo ou, ainda, ser castigadas ou mortas. Nesse caso, observa-se que a manipulação 
se dá por intimidação, ou seja, por meio do oferecimento de um objeto-valor negativo, como verificamos no frame abaixo, em que a Aia Janine (Madeline Brewer), é punida:

Figura 4 - Punição da Aia Janine
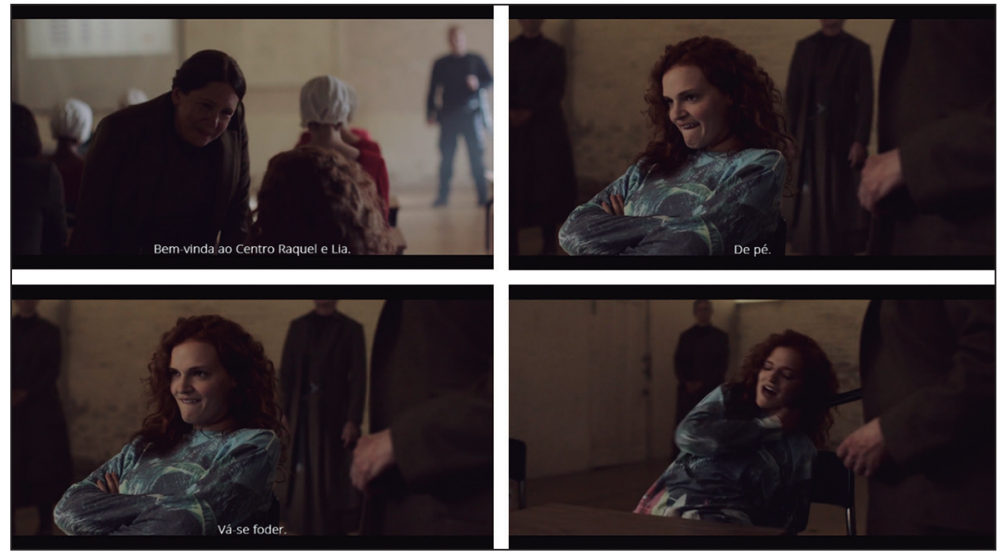

Fonte: (THE HANDMAID'S..., 2016).

Na cena, que se passa no Centro Vermelho, centro de treinamento, Tia Lydia está explicando como funciona Gilead e quais são as atribuições de uma Aia. Na continuação do episódio, Janine, que se negou a obedecer, teve como punição o olho retirado:

Figura 5 - Resultado da punição de Janine

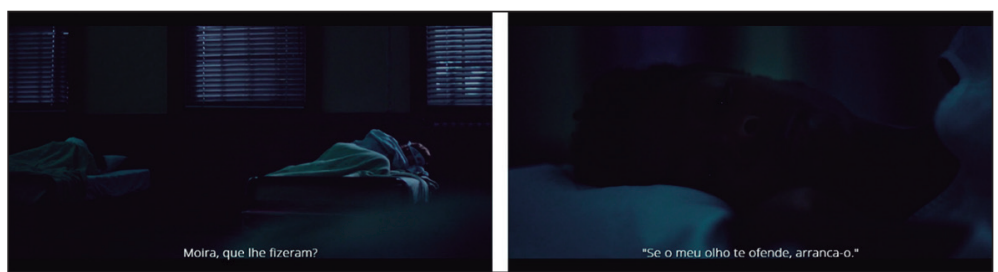

Fonte: (THE HANDMAID'S..., 2016).

Um outro tipo de manipulação, a por sedução, ocorre de maneira sutil, mas é possível notá-la quando as Tias e as Esposas fazem uma imagem positiva das Aias, mostrando-lhes que é um privilégio serem férteis e estarem ajudando a humanidade a prosseguir. Por isso, elas devem se submeter a todas as leis. Ao serem regidos pelas estratégias de manipulação, as Aias se adaptam ao regime de 
interação do sujeito-manipulador, entrando na programação, regime que rege todo o primeiro episódio da série.

Figura 6 - Rotina de Offred

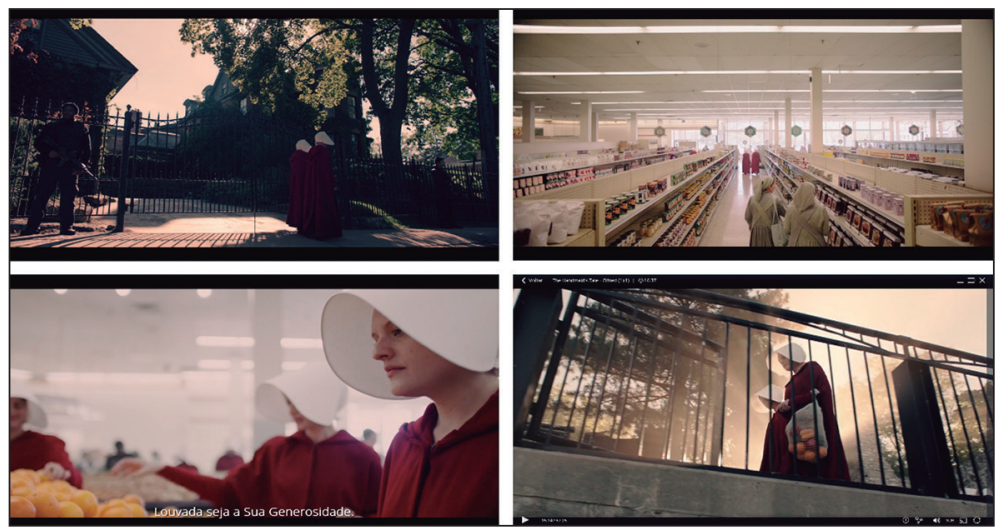

Fonte: (THE HANDMAID'S..., 2016).

No início do episódio - figura 06 -, somos introduzidos aos detalhes rotineiros do dia a dia de Offred. Ela sai para fazer compras, anda acompanhada de outra Aia, Ofglen, retorna para casa e faz tudo novamente no dia seguinte. Outro momento em que fica explícita a programação é durante a Cerimônia, um evento mensal em que o Comandante de cada família tenta engravidar a Aia.

Figura 7 - Ato da cerimônia

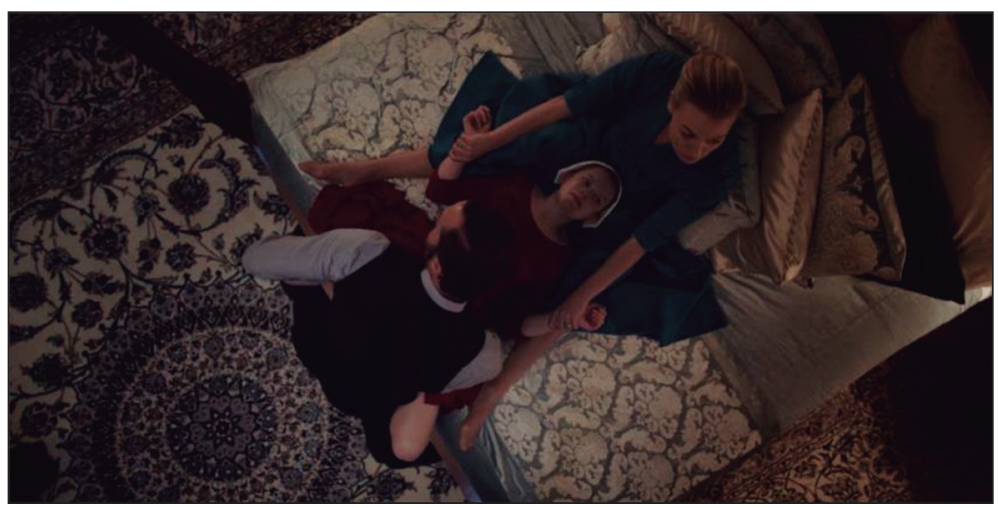

Fonte: (THE HANDMAID'S..., 2016). 
A Cerimônia é marcada por normas que devem ser cumpridas rigorosamente. $\mathrm{O}$ evento ocorre durante o período fértil da Aia e começa com a leitura do Comandante de trechos da Bíblia relacionados à passagem de Jacó, no livro de "Gênesis". Assim, pelas regras, as Aias devem ter relaçôes sexuais com o Comandante da casa onde moram, deitadas entre as pernas de esposa, que assistem a tudo. De acordo com as leis de Gilead, se as Aias não conseguirem engravidar, seguirão para outras residências até conseguirem gerar um filho.

No fim do episódio, é possível destacar mais um rito. Ao soarem três sinos, as Aias devem ir para o The Salvaging (O resgate).

Figura 8 - Badaladas para iniciar o resgate

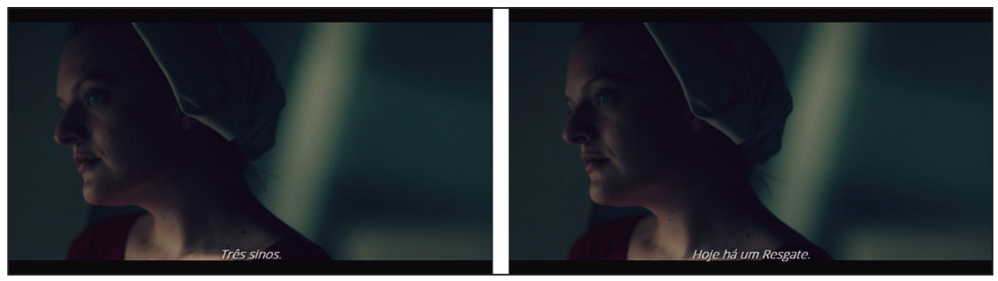

Fonte: (THE HANDMAID'S..., 2016).

O resgate é uma cerimônia da qual as Aias são responsáveis por matar sujeitos condenados por algum crime. Elas são postas lado a lado em um campo, ouvem a sentença e atacam o criminoso. Caso se neguem a executá-lo, também são condenadas. A intenção das Tias é tornar as Aias cúmplices na violência do regime. No episódio em análise, o crime cometido foi violação a uma serva grávida, que veio a perder o bebê. A pena para tal crime é a morte por meio da partixecução $o^{10}$, em que as Aias o atacam com chutes e pedras, até a morte.

$\overline{10}$ Termo sem tradução para o português, mas indica morte por chutes e pedradas. 
Figura 9 - Rito de resgate
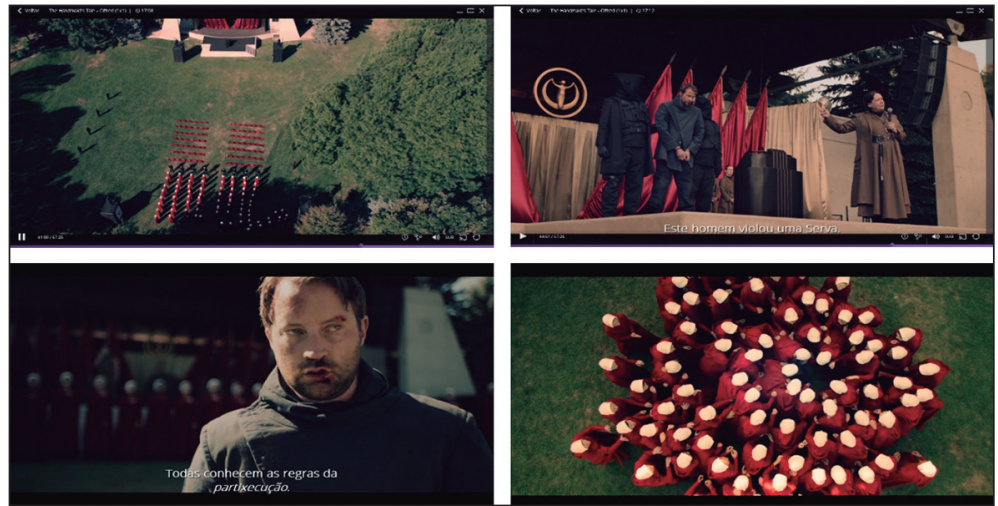

Fonte: (THE HANDMAID'S..., 2016).

Em todos esses exemplos percebemos o princípio da regularidade, que rege a programação. Segundo Landowski (2014), esse regime liga-se ao fazer-ser, uma operação na qual o indivíduo ou objeto com o qual interage possui um comportamento programado, ao qual não se poderia escapar. Por isso, o risco é praticamente nulo.

Existe, portanto, uma expectativa razoavelmente segura sobre as possíveis reaçóes e previsibilidades do que possa acontecer. A interação tem um risco mínimo, se vista pelo viés do sujeito operador que, por meio das regularidades e naturalizaçóes dos comportamentos adotados, predetermina as funçóes básicas de cada ser, ou seja, seus papéis temáticos (LANDOWSKI, 2014).

De acordo com Landowski (2014), a programação ao atingir a natureza social, proporciona um condicionamento sociocultural, no qual haverá regularidades em que o "princípio deriva de uma coerção social, ou mesmo se confunde com ela” (LANDOWSKI, 2014, p. 24). Em vista disso, durante todo o episódio, ficam claros os papéis temáticos das mulheres, que, em última instância, implicam uma regularidade de comportamento. As Aias, por exemplo, são apenas reprodutoras, tendo o papel de procriar a maior quantidade possível de vezes em suas vidas, já as Marthas, cuidam da casa e as Esposas, dos filhos e dos Comandantes.

\section{Considerações Finais}

Ao analisarmos o episódio Offred, à luz da sociossemiótica (LANDOWSKI, 2014), foi possível traçar o caminho dos regimes de interação presentes nesse 
primeiro capítulo da série The Handmaid's Tale, que parte do acidente, passa para a manipulação e, por fim, chega à programação. Por meio deles, constatamos que para analisar o regime totalitário de Gilead não podemos desvincular manipulação e programação, uma vez que há passagens graduais pelos dois regimes durante todo o episódio.

Ao partirmos da narrativa feita pela perspectiva June/Offred, notamos que a República de Gilead foi instaurada a partir da irrupção de um acidente. Devido à baixa natalidade, os Estados Unidos sofreram um golpe parlamentar e a população, principalmente as minorias, foi expulsa de seus trabalhos e teve seus direitos perdidos bruscamente, sobretudo as mulheres. Há, com a implementação do novo regime totalitário, agitação e instabilidade, a partir da descontinuidade que se instaurou: é o acidente em seu papel bruto, do risco puro e da perda de sentido.

No decorrer do trabalho, pudemos perceber que existe uma unificação em dois conceitos sobre o regime totalitário. O primeiro é que ele ocorre por meio de um poder uno do Estado, que é exercido por meio da ideologia e do medo. A ideologia presente na série é de cunho cristão - os "Filhos de Jacob" - e figurativizada na imagem de homens brancos e com alto poder social e econômico. Já o segundo é o medo, que é a força motriz que sustenta todo o percurso manipulatório e programático que rege a vida das mulheres em Gilead. O medo da morte e o das puniçóes físicas, por exemplo, fazem com que as Aias aceitem o contrato de serem escravas sexuais, com a finalidade de reprodução e, ao mesmo tempo, possam se enquadrar nas regularidades propostas pela sociedade.

Esses dois regimes - manipulação e programação - devem estar articulados, uma vez que para que as Aias estejam motivadas a realizar as açóes programadas em Gilead, de modo a se adaptarem as novas diretrizes, elas devem ter uma intencionalidade, que, no caso, é sobreviver. Mas a partir da aceitação desse contrato, passa-se àquilo que Landowski (2014) chama de programaçóes motivadas ou motivaçôes programadas, ou seja, um misto entre programação e manipulação.

Em Gilead existe um plano coletivo, com práticas ritualizadas, tais como a cerimônia, a partixecução e o próprio dia a dia das Aias, que permite desenvolver um comportamento socialmente programado. Teríamos, desse modo, o que Landowski (2014) chama de sociedade tecnocrática, em que existe um modo de organização social e político baseados no regime da programação. $\mathrm{O}$ autor cita que o tipo tecnocrático é característico de sociedades totalitárias, como é o caso de Gilead. O seu uso permite a manutenção do poder totalitário, pois se aproxima de um regime da perfeição, com um baixo risco de acidentes ou desvios. 
Evidenciam-se, também, no primeiro episódio, as funçôes programadas por meio dos papeis temáticos. As Aias têm a função de ter filhos, se não, são descartáveis. As Martas apenas cuidam dos afazeres da casa. As Tias administram o Centro Vermelho, responsável pela doutrinação das Aias. Por fim, as Esposas têm o papel de serem cristãs, mães e cuidarem da família. Assim, a identidade das mulheres se reduz a seu papel temático-funcional, do qual não conseguem se desvincular. Tal situação causa um apagamento da identidade, a partir do qual as mulheres perdem nomes e passado e, assim, apenas cumprem um papel predeterminado na sociedade.

Posto isso, podemos concluir que são as interaçóes baseadas na manipulação articuladas com as interaçóes baseadas na programação que, na sociedade distópica da série, constituem o regime totalitário. Logo, tais regimes não podem ser trabalhados isoladamente, pois as Aias, enquanto sujeitos programados, agem por uma motivação ou uma intencionalidade. Elas são, como diria Landowski (2014), indivíduos semi-programados-semi-motivados, já que possuem uma reflexão interna sobre a sociedade totalitária em que vivem, mas se esquecem (ou fingem se esquecer) que estão agindo sobre uma rígida programação.

Dessa maneira, destacamos a importância da articulação entre a manipulação e a programação. É por meio desses dois regimes de interação que a sociedade de Gilead se mantém, principalmente, ao garantir a conservação de algumas características totalitárias tais como a centralidade partidária e política nas máos de apenas um grupo, o fim dos diretos sociais e a constante presença do terror, do medo, da ameaça contra o outro. Logo, toda essa ordem é cumprida porque há uma manipulação que pressupóe a programação, mas, ao mesmo tempo, imbrica-se a ela.

\section{REFERÊNCIAS}

A BÍBLIA. Gênesis. Tradução de João Ferreira Almeida. Rio de Janeiro: King Cross Publicações, 2018.

ARENDT, H. Origens do totalitarismo: antissemitismo, imperialismo, totalitarismo. São Paulo: Companhia de Bolso, 2012.

FEITAL, Y. et al. The Handmaid's Tale: A representação da mulher na série e a proximidade com a realidade brasileira. In: SOCIEDADE BRASILEIRA DE ESTUDOS INTERDISCIPLINARES DA COMUNICAÇÃO; CONGRESSO DE CIÊNCIAS DA COMUNICAÇÃO NA REGIÃO SUDESTE, 23., 2018, Belo 
Horizonte. Anais [...], Belo Horizonte: INTERCOM, 2018. p. 01-15. Disponível em: http://portalintercom.org.br/anais/sudeste2018/resumos/R63-0598-1.pdf. Acesso em: 08 abr. 2020.

GRATON, L. A. Abençoado seja o fruto: a representação da maternidade na série The Handmaid's Tale. 119 f. 2018. Dissertação (Mestrado em Comunicação Social) Departamento de Comunicação Social, Setor de Artes, Comunicação e Design, Universidade Federal do Paraná, Curitiba, 2018.

GREIMAS, A. J. Sobre o sentido II: Ensaios semióticos. São Paulo: Nankin; Edusp, 2014.

LANDOWSKI, E. Interaçóes arriscadas. São Paulo: Estação das Letras e Cores, 2014.

NEUMANN, F. Estado Democrático e Estado Autoritário. Rio de Janeiro: Zahar Editores, 1969.

OliveIRA, A. C. de. A estética intersemiótica de Alexandre Orion. Linguagem \& Ensino, Pelotas, v. 21, p. 315-339, 2018.

SILVA, L. H. O. da. Por uma semiótica do vivido: entrevista com o sociossemioticista Eric Landowski. Casa: Cadernos de Semiótica Aplicada, Araraquara, v. 12, n. 1, p.345-361, 22 jul. 2014.

THE HANDMAID'S Tale. Direção: Bruce Miller. Los Angeles: Hulu, 2016. Primeiro episódio (58 min).

TURPIN, B. Sémiotique du langage totalitaire. In: AUBRY, L.; TURPIN, B. (dir.). Victor Klemperer: Repenser le langage totalitaire. Paris: CNRS Editions, 2012. p. 59-75.

Recebido em 05 de março de 2020.

Aprovado em 02 de junho de 2020. 